$\begin{array}{llll}\text { Submission: 02/Feb/2021; } & 1^{\text {st }} \text { round notif.: 05/May/2021; } & \text { New version: 23/May/2021; } & 2^{\text {nd }} \text { round notif.: 29/Jun/2021; } \\ \text { Camera ready: 14/Jul/2021; } & \text { Edition review: 20/Jul/2021; } & \text { Available online: 06/Aug/2021; } & \text { Published: 06/Aug/2021; }\end{array}$

\title{
Analisando o desenvolvimento do Pensamento Computacional na disciplina Matemática Discreta
}

\section{Title: Analyzing the development of Computational Thinking in Discrete Mathematics}

Walkiria Helena Cordenonzi IFSUL - Santana do Livramento walkiriacordenonzi@ifsul.edu.br

\author{
José Claudio Del Pino \\ UNIVATES \\ josepino@univates.br
}

\author{
Vanessa Mattoso Cardoso \\ IFSUL - Santana do Livramento \\ vanessacardoso@ifsul.edu.br
}

\begin{abstract}
Resumo
Este artigo aborda um estudo interdisciplinar no qual um curso sobre Pensamento Computacional (PC) foi desenvolvido em parceria com a disciplina curricular de Matemática Discreta (MD) a fim de analisar e avaliar os resultados obtidos na disciplina e compará-los com os apresentados a partir da intervenção do curso de PC, incluindo um grupo de controle. A MD é uma disciplina considerada difícil, por parte dos estudantes, por envolver muita abstração e raciocínio lógico ocasionando muita reprovação e notas baixas. Já para desenvolver o $P C$ foi utilizado o constructo andrológico proposto na tese de doutorado da primeira autora. $O$ estudo de caso foi aplicado em um curso binacional - no qual estudantes, adultos, brasileiros e uruguaios, compartilharam o mesmo espaço de aprendizagem. Por meio desta pesquisa e, a partir da análise, quanti-qualitativa, dos dados, obteve-se que 95,2\% da amostra obteve médias acima do valor de referência, 60, o que indica que o desenvolvimento do PC colaborou significativamente na resolução de problemas. Como contribuição importante apresentada a partir deste estudo foi a combinação dos instrumentos de avaliação em duas intervenções que auxiliaram o entendimento dos conceitos abordados na MD a partir do PC, bem como as escassas pesquisas de interligação de matemática com PC no âmbito do ensino superior.
\end{abstract}

Palavras-Chave: Pensamento Computacional, Matemática Discreta, Avaliação, Interdisciplinaridade.

\begin{abstract}
This article addresses an interdisciplinary study in which a course on Computational Thinking (CT) was developed in partnership with the Discrete Mathematics (DM) curricular subject to analyze and evaluate the results obtained in the discipline and compare them with those presented from of the CT course intervention, including a control group. The DM is a discipline considered difficult, on the part of the students, because it involves a lot of abstraction and logical reasoning causing a lot of disapproval and low grades. To develop the $C T$, the andragogical construct proposed in the Cordenonzi doctoral thesis was used. The case study was applied in a binational course - in which students, adults, Brazilians, and Uruguayans, shared the same learning space. Through this research and, based on the qualitative and quantitative analysis of the data, it was found that $95.2 \%$ of the sample obtained averages above the reference value, 60, which indicates that the development of the CT significantly collaborated in the resolution of problems. As an important contribution presented from this study was the combination of assessment instruments in two interventions that helped the understanding of the concepts addressed in the MD from the PC, as well as the scarce research on the interconnection of mathematics with $P C$ in the context of higher education.
\end{abstract}

Keywords: Computational Thinking, Discrete Mathematics, Evaluation, Interdisciplinarity.

Cite as: Cordenonzi, W. H., Del Pino, J. C., \& Cardoso, V. M. (2021). Analisando o desenvolvimento do Pensamento Computacional na disciplina Matemática Discreta. Revista Brasileira de Informática na Educação, 29, 880-902. DOI: 10.5753/RBIE.2021.29.0.880 


\title{
1. Introdução
}

Muitos fatores se entrelaçam quando há uma reflexão sobre os processos de ensino e de aprendizagem: como seria a melhor abordagem de metodologias e/ou de avaliações. Sempre com o fim de que o aluno aprenda, ou seja, o conhecimento recebido seja importante para sua formação.

Para um currículo, que muitas vezes, apresenta disciplinas disjuntas, com conhecimentos fragmentados e isolados, é preciso trazer a interdisciplinaridade. Os Parâmetros Nacionais Curriculares $(\mathrm{PCN})$ do ensino médio apresentam a interdisciplinaridade na perspectiva de

\begin{abstract}
[...] utilizar os conhecimentos de várias disciplinas para resolver um problema concreto ou compreender um determinado fenômeno sob diferentes pontos de vista [...] a interdisciplinaridade deve ser compreendida a partir de uma abordagem relacional, em que se propõe que, por meio da prática escolar, sejam estabelecidas interconexões e passagens entre os conhecimentos através de relações de complementaridade, convergência ou divergência. (BRASIL, 2002, p. 22).
\end{abstract}

Complementando com as palavras de Thiesen (2008, p. 3):

O que se pode afirmar no campo conceitual é que a interdisciplinaridade será sempre uma reação alternativa à abordagem disciplinar normalizadora (seja no ensino ou na pesquisa) dos diversos objetos de estudo [...] a interdisciplinaridade está sempre situada no campo onde se pensa a possibilidade de superar a fragmentação das ciências e dos conhecimentos produzidos.

No contexto desta pesquisa, entende-se a interdisciplinaridade como a integração entre conceitos, teorias, de duas (ou mais disciplinas) para um objetivo comum: desenvolver as habilidades e competências necessárias para compreender o objeto de estudo e solucionar problemas Sendo assim, buscou-se a interdisciplinaridade entre os conceitos abordados pela Matemática Discreta (MD) em consonância com o desenvolvimento do Pensamento Computacional (PC), em outras palavras, a desfragmentação dos temas das duas ciências envolvidas para um fim comum: desenvolver a capacidade de resolver problemas.

A partir do exposto, o objetivo desta pesquisa foi analisar e avaliar o desenvolvimento do PC, através do Modelo de Referência de Pensamento Computacional (W. H. Cordenonzi, 2020) e seu processo de apropriação de saberes na disciplina Matemática Discreta.

Sendo que o problema norteador da pesquisa foi verificar o impacto da integração com o pensamento computacional na aprendizagem da disciplina de Matemática Discreta. Desta forma, formulou-se a hipótese da pesquisa: o desenvolvimento do PC aporta impacto positivo no processo de compreensão dos temas desenvolvidos na MD.

Os sujeitos envolvidos nesta pesquisa são alunos inscritos no curso superior e são chamados de "alunos binacionais". Essa denominação deriva da matrícula em cursos os quais são o resultado de muitas negociações e relações bilaterais entre o governo brasileiro e o uruguaio para as cidades-gêmeas de fronteira, no caso específico: Sant'Ana do Livramento (Brasil) e Rivera (Uruguai). Em 2011, iniciam os primeiros cursos técnicos binacionais, em parceria com a Consejo de Educación Técnico Profesional - Universidad del Trabajo del Uruguay (CETP-UTU), de Rivera. Um anexo ao convênio original foi firmado entre a Universidad Tecnológica del Uruguay (UTEC), CETP-UTU e IFSUL, em 26-11-2018, como objetivo de unir esforços para a execução de atividades de ensino, pesquisa e extensão ou cooperação técnica/tecnológica em geral, priorizando o planejamento e promoção de cursos técnicos, graduação e pós-graduação binacionais relacionadas às demandas de formação técnica e tecnológica da região. Neste documento, foram incluídos os cursos superiores de Tecnólogo em Análise e Desenvolvimento de Sistemas (TADS - fonte dessa pesquisa) e Tecnólogo em Mecatrônica Industrial. Pode-se citar como diferencial destes cursos a dupla 
diplomação, a construção conjunta do projeto pedagógico, cargas horárias, a definição do português e do espanhol como línguas maternas, entre outras características (Citolin, 2013; P. H. A. Silva \& Lima, 2015). O TADS iniciou em 2019, por isso, cabe salientar que este artigo é resultado do primeiro projeto de pesquisa binacional realizado no referido curso.

A sequência deste artigo está organizada da seguinte forma: o referencial teórico está esboçado na seção 2, a seguir os pressupostos metodológicos desenvolvidos na seção 3, o estudo de caso está retratado na Seção 4. Na sequência, os resultados e discussões estão apresentados, além das conclusões compiladas. No final, as referências utilizadas estão nomeadas.

\section{Referencial Teórico}

No espaço destas indagações, no contexto desta pesquisa, torna-se importante discorrer sobre Pensamento Computacional (PC) e Matemática Discreta (MD). Quanto ao primeiro, existem diferentes entendimentos e definições acerca do conceito de PC (do inglês, Computational Thinking), porém ainda não há um consenso sobre o que é ou o que ele implica. Wing (2006, p. 33, tradução nossa) propôs esta expressão e definiu como sendo uma habilidade que "envolve a resolução de problemas, projeção de sistemas e compreensão do comportamento humano, através da extração de conceitos fundamentais da ciência da computação". Ainda, ressaltou que esta é uma habilidade fundamental a qual poderá ser utilizada por todas as pessoas, mostrandose semelhante à de ler, escrever e calcular. Outros pesquisadores (Grover \& Pea, 2013; Koh et al., 2010) também concordam que ainda é necessário entender como auxiliar os alunos a desenvolverem o PC, melhorando sua capacidade de resolução de problemas, e como deve ser o processo de aprendizagem, pois essas habilidades são fundamentais para os cidadãos do século XXI.

Além disso, sugeriu que todos os cursos superiores deveriam incorporar nos seus currículos uma disciplina que desenvolva a capacidade de resolver problemas, independentemente dos recursos computacionais. Com o passar do tempo, essa autora redefine o PC como sendo: "O pensamento computacional são os processos de pensamento envolvidos na formulação de um problema e em expressar sua(s) solução(ões) de tal forma que um computador - humano ou máquina - possa efetivamente executá-los" (Wing, 2017, p. 8, tradução nossa). Nesta pesquisa seguiu-se o entendimento desta autora.

Neste sentido, encontra-se a disciplina de Matemática Discreta (MD) que é ofertada no primeiro semestre, do curso Tecnólogo em Análise e Desenvolvimento de Sistemas (TADS), objetivando, dentre outros, a capacidade de resolver problemas, fornecendo subsídios teóricos, desenvolvendo o raciocínio lógico e introduzindo a notação matemática (linguagem formal), fundamental no estudo da ciência da computação. Ademais de explicitar a relevância e utilidade das abstrações matemáticas, direcionando o estudante para o conhecimento e desenvolvimento da programação, visto que conceitos e notações da matemática discreta são úteis para o estudo e representação de objetos, ou problemas, em algoritmos e linguagens de programação. Considerando que a MD exige a habilidade de abstração, é considerada, pelos alunos, uma das disciplinas mais difíceis deste período, ocasionando altos índices de reprovação (Amaral, 2015; V. M Cardoso \& Cordenonzi, 2017; Vanessa M. Cardoso et al., 2017; Ferreira Souza, 2018).

Fazendo-se o contraponto das habilidades trabalhadas em MD e no PC, percebe-se o mesmo objetivo: desenvolver a capacidade de resolver problemas.

Para reforçar a importância desse tema, já em caráter de justificativa, evoca-se a pesquisa colaborativa realizada pela Google e a consultoria norte-americana McKinsey \& Company 
(Martins et al., 2019), com o propósito de mapear as habilidades dos brasileiros quanto ao uso de ferramentas e tecnologias digitais. Utilizaram o Digital Skills Index (Índice de Habilidades Digitais) que possui uma escala que varia de 0 a 5 , no qual os brasileiros obtiveram nota 3 . Nesta foi concluída que:

[...] essa nota reflete que o brasileiro domina hoje muito bem as habilidades mais básicas, relacionadas a acesso, mas ainda tem grandes lacunas em competências mais técnicas, como o uso das ferramentas para a produção de conteúdo e programação. A melhora nessas atividades mais sofisticadas poderia trazer efeitos positivos no aumento da produtividade, na maior participação no mercado de trabalho, na geração de renda e na redução do desemprego. (Google, 2019,texto digital, grifo nosso)

Como se pode perceber por esse relato, é evidente para os sujeitos a necessidade de desenvolver as habilidades de $\mathrm{PC}$, bem como a programação. E em concordância com o relatório da Unesco, descrito por Delors et al. (Delors et al., 1998, p. 100, tradução e grifo nosso):

[...] é a chave que abre as portas do século XXI e, bem além de uma adaptação necessária às exigências do mundo do trabalho, é a condição para um domínio mais perfeito dos ritmos e dos tempos da pessoa humana. [...] A educação ao longo de toda a vida torna-se assim, para nós, o meio de chegar a um equilíbrio mais perfeito entre trabalho e aprendizagem bem como ao exercício de uma cidadania ativa.

Cabe ainda definir, seguindo a Unesco, no âmbito desta pesquisa, que o entendimento sobre alfabetização digital é: "[...] empoderar as pessoas em todo os aspectos da vida para buscar, avaliar, utilizar e criar informação de uma forma eficaz para alcançar suas metas pessoais, sociais ocupacionais e educativas [...]" (Wilson et al., 2011, p. 16, tradução nossa).

A seguir os trabalhos relacionados ao tema estão descritos.

\subsection{Trabalhos Correlatos}

Foi realizada uma busca no Banco de Teses e Dissertações da CAPES (BTD), com as palavraschave "pensamento computacional" (em 25-04-2020) resultaram 14 teses de Doutorado e 72 dissertações de Mestrados, a partir de 2009. Destas últimas, apenas 9,7\% descreveram o PC interligando os conhecimentos com a matemática. Cabe salientar que todas as experiências relatadas foram realizadas no ensino básico.

Barcelos (2014), em sua tese de doutorado, integrou o PC aos conhecimentos matemáticos através de jogos digitais, em sujeitos cursistas do ensino médio. Baseou seu trabalho nos princípios do construcionismo e a aprendizagem Baseada em Problemas (ABP), baseando-se na teoria de Vygotsky. Já Costa (2017, p. 3), teve como objetivo, em sua pesquisa, "estimular a capacidade de resolução de problemas nos alunos, por meio da própria disciplina de matemática, estimulando as competências essenciais através de atividades práticas utilizando questões em maior conformidade com o Pensamento Computacional". Os resultados foram positivos, evidenciando que os sujeitos envolvidos melhoraram a capacidade de resolução de problemas.

Por outro lado, Mestre (2017) propôs algumas estratégias para resolução de problemas matemáticos por meio de um mapeamento entre as Capacidades Fundamentais da Matemática e os Conceitos do PC, não detalhando o nível de ensino no qual a pesquisa foi ancorada.

$\mathrm{Na}$ dissertação de Silva (2018), está descrita sua experiência com alunos do Ensino Fundamental, a qual visava estimular nos estudantes o desenvolvimento do PC para estudarem e aprenderem os conteúdos matemáticos envolvidos naquelas atividades. $O$ tema escolhido na matemática foi o resto da divisão euclidiana e congruência entre números inteiros, já para o desenvolvimento do PC utilizaram kits de robótica Arduino Uno e programação com o software 
Scratch for Arduino. Os resultados apontaram que o desenvolvimento do PC oportunizado pela manipulação dos kits de robótica, contribuíram para a formação de conceitos matemáticos dos estudantes envolvidos.

Alguns estudos envolvendo o PC com estudantes de nível superior estão citados, como por exemplo, os pesquisadores Koh et al. (2010) desenvolveram a ferramenta CTPG (Computational Thinking Pattern Graph) para a avaliação semântica de jogos e simulações e aplicaram em vários grupos de estudantes universitários.

Um estudo de caso (em formato de curso, semelhante a esta pesquisa) com estudantes do Curso de Ciência da Computação na Universidade de Montana (Van Dyne \& Braun, 2014) sobre $\mathrm{PC}$, chegaram à conclusão sobre o impacto significativo na melhoria das habilidades de resolução de problemas.

Já na Universidade de Rhodes (África do Sul), foi aplicado um teste para avaliar o desenvolvimento das habilidades do $\mathrm{PC}$ em estudantes do primeiro semestre de um Curso de Computação. Este teste foi aplicado para avaliar os saberes dos estudantes antes de os alunos iniciarem um conhecimento formal dos conteúdos e concluíram que o PC não é uma habilidade que possa ser desenvolvida nos alunos, portanto, sugerem que mais estudos deveriam ser realizados (Gouws et al., 2013).

Na tese de Araújo (2019), a autora descreve a experiência de desenvolvimento de PC em duas amostras realizadas em cursos de Ciência da Computação para investigar estratégias e instrumentos para quantificar as habilidades de PC de maneira confiável, sem práticas de programação obrigatórias.

A seguir os pressupostos metodológicos estão discorridos.

\section{Pressupostos Metodológicos}

Uma pesquisa científica inicia quando há um problema que pode ser resolvido (Gil, 2002). Assim, a partir da questão descritiva do problema a ser investigado, as hipóteses foram formuladas e a investigação tomou forma para ser realizada. Triviños (2015) adiciona que o problema de investigação é um contexto que precisa ser elucidado.

Verificou-se que o campo de pesquisa, desenvolver e avaliar a MD, ou Matemática do ensino superior de forma mais ampla, sobre a perspectiva do PC, ainda apresenta muitas lacunas a serem investigadas.

Este trabalho foi realizado seguindo o método indutivo, com estudo de caso, comparação e avaliação dos resultados de forma qualitativa e quantitativa. Também foram desenvolvidos os documentos exigidos pela Resolução no 466/2012 (Conselho Nacional de Saúde) do Brasil, como o Termo de Consentimento Livre e Esclarecido (TCLE) e a Carta de Anuência da Instituição e devidamente assinados. Esta pesquisa está registrada no Comitê de Ética sob o número 3.551.029. Os integrantes da pesquisa são os alunos dos cursos binacionais, que incluem alunos brasileiros e uruguaios de diferentes origens. Portanto, as línguas maternas nesses cursos, ao mesmo tempo, são o português e o espanhol (W. Cordenonzi et al., 2014).

Para obtenção dos resultados, foram avaliados o desenvolvimento dos estudantes, em separado, no que diz respeito ao PC e à MD (Turma 1: 2019/01), na sequência observados e comparados estes resultados a fim de corroborar este estudo.

Com o propósito de tornar os estudos mais significativos, quanto à sua interpretação, foi incluída uma amostra de controle (Turma 2: 2019/02), na qual o andamento da disciplina MD 
se deu sem a intervenção do PC, sem o curso, com atividades semelhantes às descritas no item 3.2.2.

No semestre seguinte, não houve a interação do grupo de alunos matriculados na disciplina MD com o PC, sendo, portanto, considerado este como o grupo de controle, cuja amostra contou com 24 sujeitos, mostrado na Figura 1.

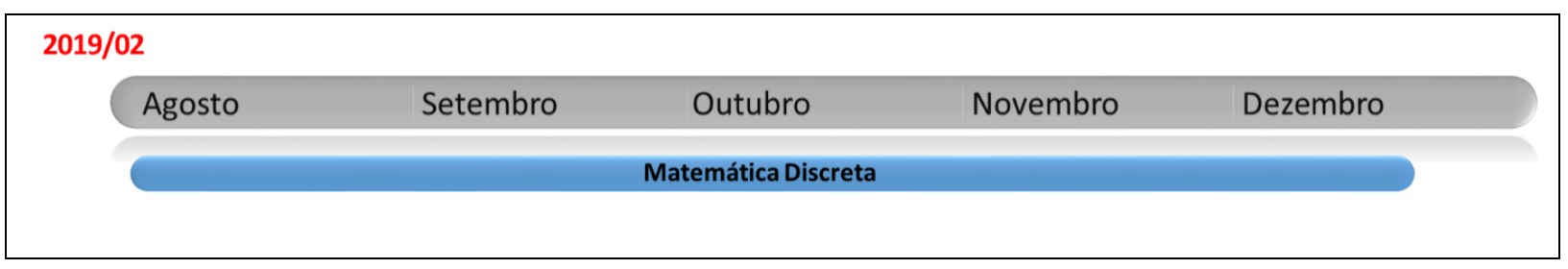

Figura 1 - Matemática Discreta - grupo controle.

Fonte: Autores (2021).

Foi proposto um constructo andragógico (descrito em 3.1.1), no qual há um conjunto de materiais instrucionais para a realização do curso, denominado de "Eu Programo 1.0!" e um método de avaliação do desenvolvimento do PC, apresentado na seção seguinte.

Cabe explicitar que se convencionou que os pesquisadores foram nomeados por P1 (atuando na MD) e P2 (desenvolvendo o curso de PC).

A seguir estão descritas as formas como as avaliações aconteceram em ambas as partes do EC.

\subsection{Método de avaliação}

Nesta seção estão descritas as duas formas que o processo avaliativo foi conduzido. Ou seja, no curso "Eu Programo 1.0!", através do Modelo de Referência de Pensamento Computacional, e a forma de avaliação da disciplina de MD. A partir da análise destas avaliações, em uma primeira instância separadamente, a fim de culminar no conjunto de saberes apropriados ou não pelos sujeitos. Cabe salientar que a forma como as avaliações foram concebidas e praticadas foi projetada com o propósito de descrever o processo e a análise das tarefas avaliativas sobre cada tema. Dessa forma, pode-se compreender o processo de ensino e aprendizagem dos sujeitos envolvidos.

\subsubsection{Descrição e avaliação do curso "Eu Programo 1.0!"}

O curso "Eu Programo 1.0!" foi definido com duração de 20 horas. A recomendação seguida foi que a cada aula um ou mais conceitos fossem apresentados ao aprendiz de forma rápida, quer dizer, não mais do que 10 minutos de apresentação, e segue-se a sua aplicação, em suma, a prática (programação). Knowles (1973) observou que as informações lembradas são as recebidas nos primeiros 15 minutos de aula. Já para Cavalcanti (1999, texto digital), os adultos "podem se concentrar numa explanação teórica durante 07 minutos. Depois disso, a atenção se dispersa". Ainda, esse mesmo autor complementa que, neste intervalo de tempo, o professor poderá utilizar para apresentar "os objetivos e a relevância do assunto a ser discutido, enfatizar o valor deste conhecimento e dizer o quanto se sente motivado a discuti-lo" (texto digital).

Para executar a prática com os alunos, foi escolhido o software App Inventor. A escolha dessa ferramenta foi porque, a partir de uma interface simples, intuitiva, o usuário é capaz de desenvolver seus aplicativos em pouco tempo. Em outras palavras, já nos primeiros encontros o aluno consegue desenvolver um aplicativo simples. Para o desenvolvimento de cada aula, basicamente, observou-se o seguinte roteiro: apresentação e/ou retomada dos conceitos; construção do App e teste. Após construir o App em aula, foi sugerido ao aluno um desafio (a fim de incentivar a aprendizagem por descoberta). Este consiste em propor uma melhoria ou alteração no aplicativo, a fim de verificar se houve aprendizagem por parte do discente. Quer 
dizer, parte-se do todo para as partes, conforme sugerem Knowles, Holton e Swanson (2011, p. 233): que "organização do conhecimento deve ser a preocupação essencial do professor ou de quem planeja a educação, de maneira que o trajeto do simples ao complexo não ocorra de partes arbitrárias e sem sentido a todos significativos, mas sim de todos simplificados a todos mais complexos".

Foi determinado que, quando o aluno terminasse o seu App ${ }^{1}$, este fosse enviado ao P2, a fim de realizar a correção e retornar um feedback, porque "sabemos que a andragogia deve ser mais personalizada para se adequar à singularidade entre os adultos" (Knowles et al., 2011, p. 146), assim o foco da aprendizagem está no aluno e cabe ao professor/tutor acompanhar esse processo.

Todos os materiais construídos foram disponibilizados para os sujeitos em um ambiente virtual de aprendizagem (AVA), que serviu tanto de repositório de materiais quanto para a comunicação dos alunos com o professor. Também permitiu a implementação da Comunidade de Prática $^{2}(\mathrm{CoP})$.

Considerando o posicionamento de Ausubel (2003, p. 21), quando descreve que "a aprendizagem por recepção verbal não é necessariamente memorizada ou passiva (tal como o é frequentemente na prática educacional corrente), desde que se utilizem métodos de ensino expositivos baseados na natureza, condições e considerações de desenvolvimento que caracterizam a aprendizagem por recepção significativa", as aulas foram planejadas, juntamente com os materiais instrucionais, na sua maioria, para serem verbal-expositivas, ou seja, o professor, junto com os alunos, vai construindo o App, explicando e questionando cada comando ou grupo de comandos executados. Ainda, houve preocupação com a recomendação sobre o cuidado quanto aos seus materiais de instrução, além de atender a autonomia do aluno (Knowles et al., 2011).

Foram propostos 7 aplicativos, descritos resumidamente na Tabela 1. Os dois primeiros aplicativos foram construídos para que o usuário entenda o funcionamento da ferramenta. Para os demais buscaram-se temas que fossem da realidade do aluno agregando conhecimentos da MD e dos seus interesses, pois, conforme Knowles, Holton e Swanson (2011, p. 74), "os adultos ficam prontos para aprender as coisas que têm de saber e para as quais precisam se tornar capazes de realizar a fim de enfrentar as situações da vida real". Em síntese, quanto à escolha dos temas dos aplicativos, o modelo andragógico de Knowles foi um dos principais referenciais, assim fomentando no aprendiz a necessidade do saber entrelaçado com o trabalho colaborativo com a MD.

\footnotetext{
${ }^{1}$ Ferramenta de criação de App, disponibilizada gratuitamente na internet pelo MIT (disponível em: http://ai2.appinventor.mit.edu/).

${ }^{2}$ Esta denominação e seus respectivos conceitos sobre Comunidade de Prática $(\mathrm{CoP})$ foram propostos por Wenger (2002), a partir de seus estudos sobre modelos de aprendizagem. Atualmente é muito utilizado na área de administração de empresas, pois auxilia os indivíduos a desenvolver não somente a aprendizagem como também as competências organizacionais. Essa autora define CoP como sendo um grupo de pessoas que compartilham uma paixão sobre algo que sabem fazer e que interagem para aprender como fazê-lo melhor (Wenger, 2002).
} 
Tabela 1 - Resumo dos conceitos e práticas dos App

\begin{tabular}{|c|c|c|}
\hline Nome do Aplicativo & Tema/Conceito & Prática \\
\hline Gato & - Uso das ferramentas tecnológicas & $\begin{array}{l}\text {-Uso do ambiente da ferramenta: } \\
\text { menu, palette, viewer, Components, } \\
\text { Properties, abas Projects e Connect, } \\
\text { Interface (Designer) e Blocks Editor } \\
\text { (programação). }\end{array}$ \\
\hline Tradutor & $\begin{array}{l}\text { - Eventos simples } \\
\text { - Seleção de componentes no Designer e } \\
\text { comportamento no Blocks Editor; } \\
\text { - Componentes visível e não-visível; } \\
\text { - Manipulação de Propriedades dos } \\
\text { componentes; } \\
\text { - Salvar App no dispositivo móvel. }\end{array}$ & $\begin{array}{l}\text { - Construção de um aplicativo (App) } \\
\text { que utiliza os temas citados; } \\
\text { - Teste do App; } \\
\text { - Geração do App para salvar no } \\
\text { dispositivo móvel; } \\
\text { - Desafio para os alunos para } \\
\text { aumentar as funcionalidades do App } \\
\text { (repete para todos). }\end{array}$ \\
\hline Combustível & $\begin{array}{l}\text { - Início da Programação: variável (global e } \\
\text { local), comando de condição (if/then/else), } \\
\text { operadores lógicos, aritméticos e relacionais; } \\
\text { - Uso de funções matemáticas }\end{array}$ & $\begin{array}{l}\text { - Uso da aba Projects e Connect, } \\
\text { Projeto de Interface (Designer) e } \\
\text { Blocks (programação); } \\
\text { - Testes. }\end{array}$ \\
\hline $\begin{array}{c}\text { Pedômetro ou } \\
\text { Contador de Passos } \\
\text { e Calorias }\end{array}$ & $\begin{array}{l}\text { - Programação de variável, comando } \\
\text { condicional, eventos do sensor de caminhada, } \\
\text { concatenação de comandos, cálculo } \\
\text { matemático; } \\
\text { - Uso de funções, expressões, cálculo } \\
\text { proposicional. }\end{array}$ & $\begin{array}{l}\text { - Uso da aba Projects e Connect, } \\
\text { Designer e Blocks; uso da Paleta de } \\
\text { Sensores (Pedômetro) e Mídia } \\
\text { (som); } \\
\text { - Testes. }\end{array}$ \\
\hline Calculadora & $\begin{array}{l}\text { - Programação de variável, comando } \\
\text { condicional, comando de repetição, } \\
\text { concatenação de comandos, cálculo } \\
\text { matemático; } \\
\text { - Uso de funções, expressões. }\end{array}$ & $\begin{array}{l}\text { - Uso da aba Projects e Connect, } \\
\text { Designer e Blocks; } \\
\text { - Testes. }\end{array}$ \\
\hline Fatorial e Câmbio & $\begin{array}{l}\text { - Programação de variável, comando de } \\
\text { repetição, operadores matemáticos e lógicos, } \\
\text { cálculo matemático; } \\
\text { - Uso de funções, análise combinatória, cálculo } \\
\text { proposicional. }\end{array}$ & $\begin{array}{l}\text { - Buscar o App na Galeria do App } \\
\text { Inventor (repositório) e } \\
\text { compartilhar seu aplicativo com a } \\
\text { comunidade; } \\
\text { - Uso da aba Projects e Connect, } \\
\text { Designer e Blocks; } \\
\text { - Testes. }\end{array}$ \\
\hline Projeto Final: $Q U I Z$ & $\begin{array}{l}\text { Aplicação dos conceitos ancorados; } \\
\text { - Cálculo proposicional, teoria dos conjuntos, } \\
\text { funções e análise combinatória. }\end{array}$ & $\begin{array}{l}\text { - Uso de listas; } \\
\text { - Testes. }\end{array}$ \\
\hline
\end{tabular}

Fonte: Adaptado de (W. H. Cordenonzi, 2020).

A calculadora foi projetada para introduzir os conceitos sobre operadores matemáticos, além de trabalhar com os conceitos de condição. Por exemplo: mostrar ao usuário uma mensagem que a operação de divisão não poderá ser executada pelo número 0 . Já o App Fatorial, foi planejado para calcular o fatorial de um número, porém utilizando diferentes comandos de repetição. Na primeira resolução o aluno deve implementar este cálculo utilizando o comando FOR, na segunda resolução o comando WHILE. 
E, por fim, 'Cambio' é um aplicativo muito útil e totalmente coerente com a realidade dos sujeitos. Nas cidades-gêmeas, é comum em qualquer estabelecimento comercial fazer o pagamento em qualquer moeda, a saber, em Real ou Peso. Para começar a usar o aplicativo, deve-se informar o valor da cotação entre as duas moedas, conforme pode ser visualizado na Figura 2. Depois, informa o valor do produto (em pesos), o valor das notas que está pagando e em qual moeda, e o aplicativo calcula o valor do troco na mesma moeda indicada.

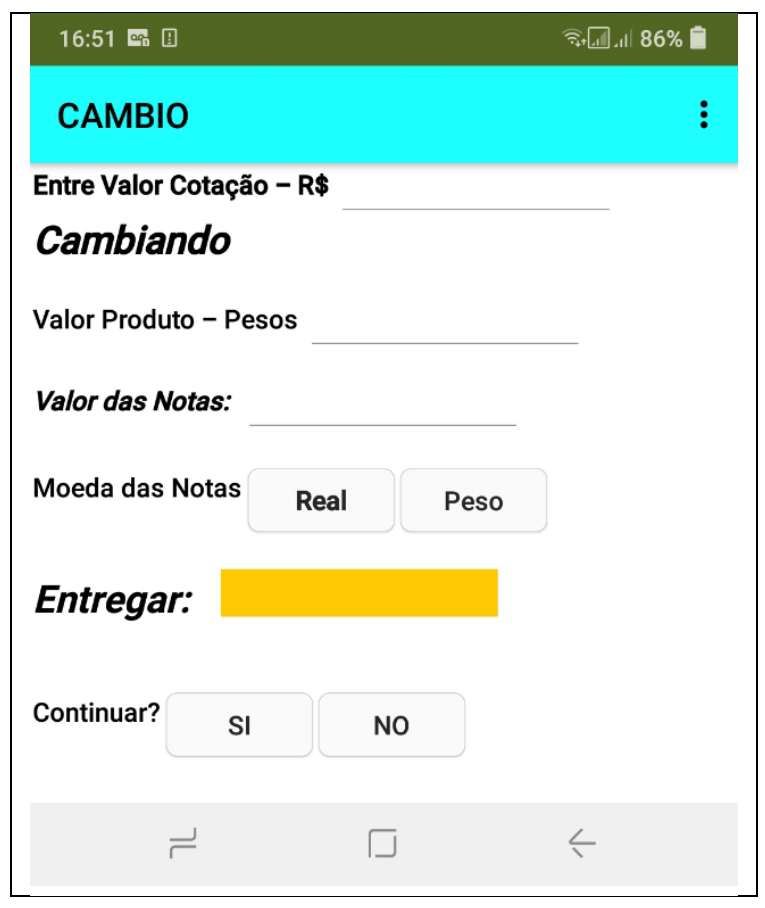

Figura 2 - Interface do App Cambio. Fonte: Autores (2021).

A Figura 2 é a captura da tela em um dispositivo móvel, que representa o App tal como será mostrado para o usuário. No campo destinado a informar o valor da cotação, é executado somente uma vez, pois a cotação permanece inalterada, enquanto o aplicativo estiver em uso.

Ao final do curso, foi previsto o desenvolvimento de um programa do tipo Quiz (projeto final), para que os sujeitos apresentassem um App sobre os temas estudados na disciplina MD.

Brennan e Resnick (2012) propuseram sugestões para avaliar o desenvolvimento do PC através da programação. Embora seu trabalho esteja focado no nível K-12, julgou-se importante considerar alguns aspectos deles para esta pesquisa. Por exemplo, a recomendação de que muitos projetos sejam desenvolvidos ao longo do processo a fim de oportunizar ao professor o entendimento do pensamento de cada aluno. Outra observação relevante considerada foi a existência de vários pontos de verificação da aprendizagem durante os encontros.

Como avaliar não é um processo simples, neste curso foi utilizado o constructo andragógico proposto em Cordenonzi (2020) que contém um Modelo de Referência de PC (MRPC) e um método de avaliação sobre desenvolvimento de PC. A partir do uso deste método, é possível a classificação dos sujeitos em alfabetizados em código (Acod) ou pensador computacional Desplugado - PCD (sujeito que apresenta as habilidades de abstração e resolução de problemas, porém não é capaz de escrever a solução de forma algorítmica). Na Figura 3, o processo de avaliação, através de um fluxograma, é mostrado. 


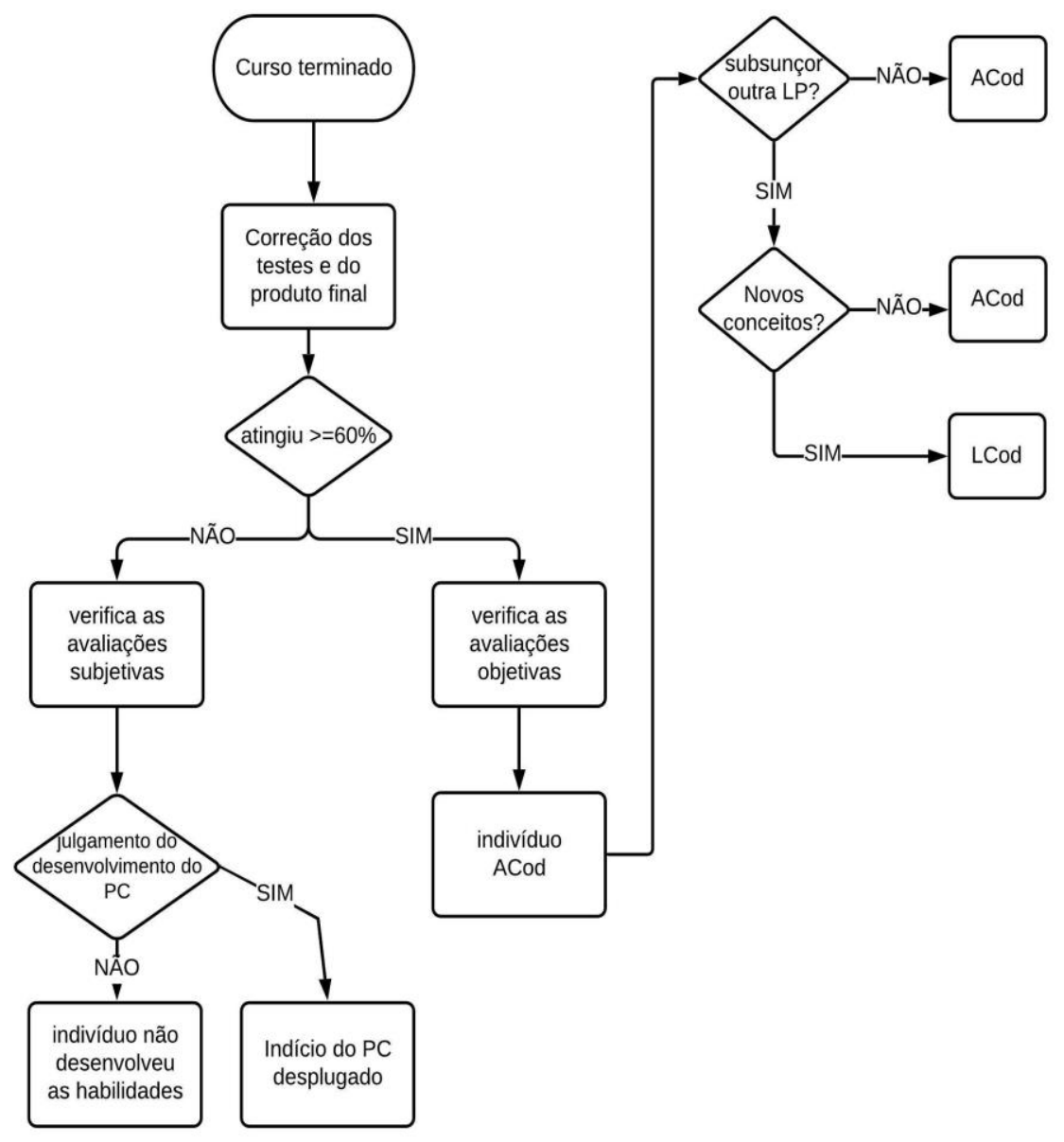

Figura 3 - Processo de avaliação.

Fonte: (W. H. Cordenonzi, 2020).

Após ser aplicado o método de avaliação, inclusive o projeto final (App) entregue e devidamente avaliado, fez-se a média dos valores encontrados. Com esses valores conhecidos, pode-se sugerir o status do indivíduo quanto à alfabetização em código (Acod). Já para a avaliação subjetiva, o pesquisador deverá avaliar de forma individual cada aluno e então determinar, conforme descrito no constructo andragógico, se o discente desenvolveu todas as habilidades propostas no MRPC, juntamente com as observações realizadas durante todo o curso e na Comunidade de Prática $(\mathrm{CoP})$. Então, o pesquisador poderá sugerir que o aluno desenvolveu o PC, porém de forma desplugada. Os sujeitos considerados Letrados em Código (LCod), são aqueles que são, obrigatoriamente, alfabetizados em código em, pelo menos, uma linguagem de programação e apresentam conhecimento de comandos mais complexos (em relação aos exigidos para aos indivíduos alfabetizados em código) (W. H. Cordenonzi et al., 2020). A seguir, será mostrado o detalhamento da abordagem da disciplina MD, quanto à sua forma de desenvolvimento, sob responsabilidade da P1.

\subsubsection{Matemática Discreta}

No início do semestre os estudantes, ao receberem o plano de ensino da disciplina, tomaram conhecimento do projeto interdisciplinar (gerando dados para um estudo de caso) e que, antes do seu início, foi necessária uma base (organizadores prévios) fornecida pela Matemática Discreta.

Desta forma, com intuito de preparar os estudantes com alguns conceitos, desenvolver o raciocínio lógico e prepará-los para a abstração matemática, através da formalização, foram 
abordados os seguintes temas: fundamentos da lógica, teoria dos conjuntos, relações e funções (em linguagem de programação) e técnicas de demonstração.

Estes conteúdos foram abordados a partir de aulas verbal-expositivas, pesquisa e muita prática, por meio de situações problemas: de forma individual e coletiva, começando com foco na resolução numérica, percorrendo o raciocínio lógico, com encaminhamento a formalização, instigando os estudantes a pensarem como programadores.

Nesta primeira etapa, as avaliações foram constituídas de provas teóricas e trabalhos (resolução de problemas) em equipes.

Como o objetivo da proposta foi de ter no PC um aliado para a significação da MD, a distribuição dos valores da avaliação ficou em $50 \%$ para atividades conceituais de MD e os outros 50\%, avaliados no decorrer do estudo de caso (EC), visto que neste os estudantes precisam aplicar os conhecimentos prévios de MD e, ainda, explorar novos (de conteúdos da disciplina).

Os primeiros $50 \%$ foram distribuídos em três avaliações: dois trabalhos, duplas, valendo 15 pontos cada e uma avaliação individual, prova, com valor de 20 pontos.

Na sequência, deu-se início ao EC, no qual os alunos tiveram que aplicar os conhecimentos de MD no desenvolvimento de aplicativos visando resgatar conceitos, tratar os temas no viés do PC, revisando os conteúdos apropriados e buscando a apropriação dos demais.

Até então, foi exposto a organização da disciplina quanto ao delineamento avaliativo na turma participante do curso de PC. Com relação ao chamado grupo de controle, turma 2019/02, a disciplina foi ministrada e avaliada, na íntegra, de acordo com os critérios descritos nos primeiros $50 \%$ deste estudo de caso.

\section{Estudo de Caso (EC)}

O estudo de caso foi desenvolvido, conforme já citado, no curso de TADS, mais especificamente no primeiro semestre, da primeira turma ingressante do ano de 2019. A pesquisadora P2 desenvolveu o curso de PC e a P1 foi a responsável pela disciplina de Matemática Discreta.

O diagrama a seguir (Figura 4) apresenta o desenvolvimento das atividades realizadas com a turma, nos diferentes momentos.

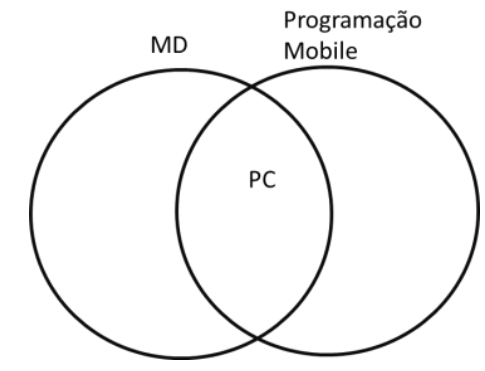

Figura 4- Atividades Interdisciplinares. Fonte: Autores (2021).

Conforme a Figura 4, o desenvolvimento se deu em 3 momentos, muitas vezes concomitantes, no semestre de 2019/01, estando o trabalho interdisciplinar (PC) representado na intersecção entre conceitos, e práticas, de MD e Programação. 
$\mathrm{Na}$ disciplina MD precisou, inicialmente, revisar conceitos como teoria dos conjuntos (do Ensino Médio) para introduzir as teorias e os conteúdos desta ciência e trabalhar no sentido do PC.

Da mesma forma, os alunos precisaram conhecer o funcionamento do ambiente de programação (App Inventor) com o qual iriam desenvolver seus aplicativos, para assim conseguir integrar os conhecimentos e desenvolver a capacidade de resolver problemas cotidianos.

O curso de PC ("Eu Programo 1.0!") foi ministrado nos horários correspondente às aulas de $\mathrm{MD}$, e contou com a colaboração da P1 para que as dúvidas relativas ao desenvolvimento e entendimento dos conceitos matemáticos, envolvidos na elaboração dos App, fossem entendidos e devidamente ancorados na estrutura cognitiva dos sujeitos.

Neste EC, foram considerados 21 sujeitos na amostra, pois foram estes que terminaram o semestre e o estudo de caso, cumprindo todas as atividades propostas. Destes infere-se que a turma é constituída de $47 \%$ brasileiros e 53\% uruguaios; que a média de idade é de 22,04 anos (considerando que um sujeito respondeu como zero) e que $80,9 \%$ são homens e $19 \%$ são mulheres.

Foram realizados 10 encontros, embora no Plano de Aula tenham sido planejados somente 8, de uma hora e trinta minutos cada um, no Laboratório de Informática e os computadores foram previamente preparados para que os softwares necessários estivessem disponíveis.

No início das atividades foi apresentado aos sujeitos o objetivo do curso e sua importância, sendo solicitado a assinatura do Termo de Consentimento Livre e Esclarecido (TCLE), o qual foi assinado pelos 27 alunos presentes. Também responderam ao questionário "Conhecendo Você", no AVA, com a finalidade de se obter dados pessoais e sobre os subsunçores de programação. Todos os sujeitos já apresentaram subsunçores com relação ao uso do AVA; portanto, não foram necessários maiores esclarecimentos, sendo, então, um indicativo de que no grupo todos estão alfabetizados digitalmente.

Com relação ao interesse desse grupo formado por adultos, se recomenda que sejam propostos problemas da vida cotidiana (Knowles et al., 2011). Acredita-se que o indivíduo, matriculado em um curso na área da Computação, será um programador e que, consequentemente, terá de desenvolver soluções para outras pessoas ou empresas. $\mathrm{O}$ fato do aplicativo final ser um jogo motivou os aprendentes, porque muitos sinalizaram que nunca haviam se aventurado nessa área.

Então, no oitavo encontro, foi implementado o conceito de listas, bem como outras possíveis soluções foram sugeridas, como, por exemplo, que cada resposta pode ser atribuída a um componente do tipo botão. Um App em aula foi desenvolvido a fim de experienciar os novos componentes. Por solicitação dos alunos, a P1, no encontro seguinte, revisou os conceitos matemáticos necessários à resolução e implementação do Quiz, no qual deveria disponibilizar quatro alternativas para que o usuário selecione a correta.

Desta forma, após a aula conceitual, análise combinatória, os estudantes receberam uma pequena lista com questões que deveria, no primeiro momento, serem resolvidas, de forma manual, utilizando-se dos conceitos abordados na aula expositiva.

Houve uma participação intensa dos alunos que perceberam a importância dessa aprendizagem para a correta implementação do jogo de perguntas e respostas. A Figura 5 e a Figura 6 mostram, em diferentes ângulos, o Laboratório de Informática, em um dos encontros. 


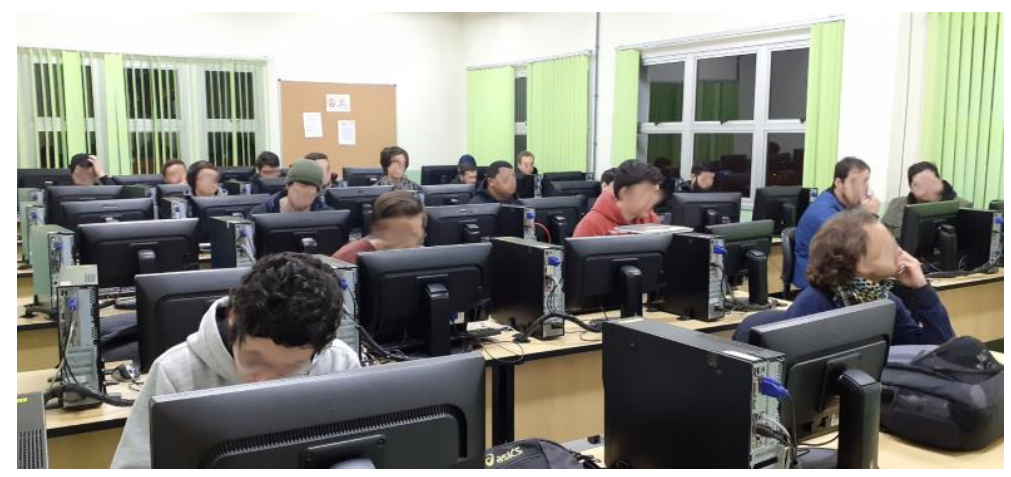

Figura 5 - Alunos fazendo suas atividades. Fonte: (W. H. Cordenonzi, 2020).

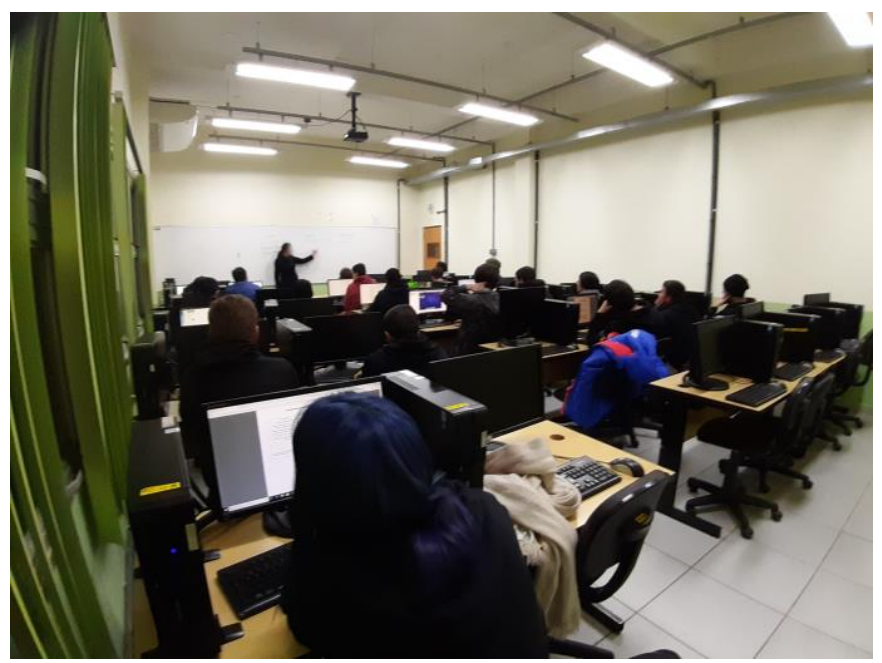

Figura 6 - Intervenção da P1. Fonte: (W. H. Cordenonzi, 2020).

E, por fim, o último encontro, foi reservado para o desenvolvimento do projeto final, ou, pelo menos, parte dele, com o intuito de auxiliar os sujeitos na administração do seu tempo, pois os alunos estavam terminando o semestre, fato que pode ser traduzido com o acúmulo de trabalhos e provas, e, ademais, que nove alunos apontaram que trabalham durante o dia. $\mathrm{O}$ resumo dos encontros está apresentado na Figura 7.

Além disso, cada aluno foi designado como testador de dois aplicativos, programados por seus colegas, sendo que esta tarefa foi com o intuito de estudar os conteúdos matemáticos. Nesta atividade de teste, o aluno/testador deveria observar e avaliar os seguintes itens:

a) Interface: verificar se todos os elementos aparecem, se é amigável ao usuário e se a navegação está apropriada;

b) Programação correta: contador exato para o número de acertos e apresentação de todas as questões;

c) Resposta: resultado das questões está correto. 


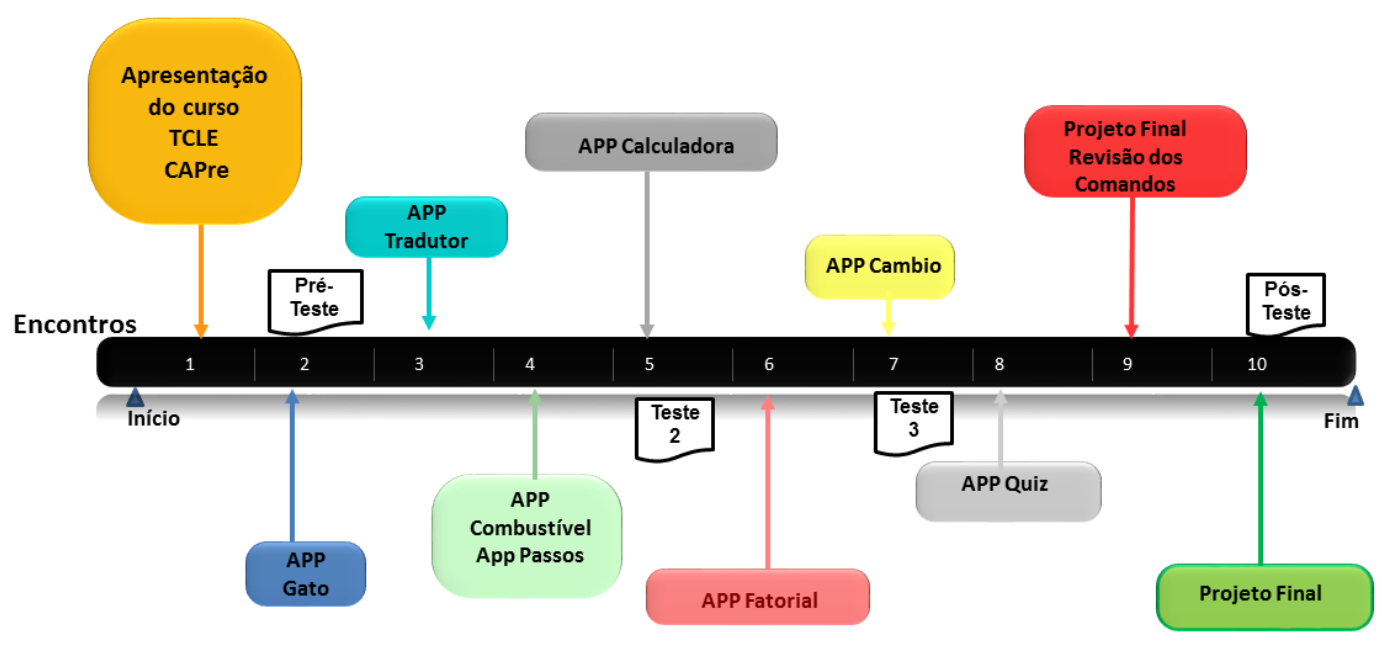

Figura 7 - Timeline das atividades.

Fonte: (W. H. Cordenonzi, 2020).

Esta atividade gerou a última parte da nota da disciplina de MD: através desse curso avaliou-se o conhecimento dos conteúdos anteriores, na ótica do Pensamento Computacional, bem como a compreensão da análise combinatória. Sendo esta avaliação dividida em duas partes: desenvolvimento do algoritmo para resolução dos exercícios e estrutura do Quiz (20 pontos) e teste do aplicativo do colega (resolução de exercícios do conteúdo) os últimos 10 pontos. Finalizando assim os 100 pontos máximos da disciplina mencionada.

\section{Resultados e Discussões}

Neste artigo foi apresentado uma pesquisa realizada na primeira turma do curso superior TADS de um curso binacional, apresentando um trabalho interdisciplinar envolvendo os conceitos da disciplina MD e de PC. Foram coletados dados de 20 sujeitos, destes 47,6\% são brasileiros e o restante de nacionalidade uruguaia. Embora o foco desta pesquisa tenha sido a integração dos conhecimentos destas áreas já citadas, é importante, tanto para a construção da história do curso, quanto para as duas instituições envolvidas em ofertar este curso superior, o detalhamento sobre a formação anterior dos sujeitos, a partir de sua nacionalidade. Por ser um curso binacional com igualdade de vagas (50\% para cada nacionalidade) foram registrados, também, dados por nacionalidade. Porém, como esta foi uma turma e um projeto piloto, por não possibilitar a comparação, estes dados não foram mais explorados e a nacionalidade não foi o foco desse estudo.

Com respeito aos sujeitos, quando questionados se sabiam programar, 76,19\% (16) responderam que sim. Deste grupo, 12 sujeitos declararam que já haviam frequentado cursos de informática na área de programação em nível de Ensino Médio (que equivale ao bachillerato no Uruguai) ou subsequente. De acordo com os depoimentos registrados por parte dos sujeitos, a maioria deseja aprender a programar a fim de conquistar melhores trabalhos, conforme pode ser citado: "Poder ter um bom emprego e aprender sobre a profissão que mais cresce no mundo" e "Mejorar mis conocimientos en el área y conseguir mejores oportunidades de trabajo". Pode-se perceber que entendem a importância sobre a programação (do PC) no contexto atual do mercado de trabalho.

Ficou evidente que todos os alunos, mesmo os que declararam que não sabiam programar, demonstraram conhecimentos básicos sobre conceitos de algoritmos e variáveis. Manteve-se a 
solicitação de que os aplicativos desenvolvidos fossem compartilhados com a turma no AVA assim que fossem finalizados ou no término do encontro. Sempre na aula posterior, para os App que estavam disponíveis, um feedback era realizado. Os sujeitos que declararam que não sabiam programar, durante as aulas receberam uma atenção especial. Durante os encontros, alguns alunos buscavam sanar suas dúvidas sobre o feedback, por exemplo, perguntando onde haviam errado ou o que poderiam fazer para melhorar o App. Isso demonstrou o interesse despertado e a motivação para aprender por parte dos sujeitos.

O resumo das avaliações por tema e por aluno está delineado na Tabela 2.

Tabela 2 - Resultado das Avaliações por Aluno.

\begin{tabular}{|c|c|c|c|}
\hline & $\begin{array}{c}\text { Resultado da avaliação } \\
\text { objetiva do Curso } \\
\text { Eu Programo 1.0! }\end{array}$ & $\begin{array}{l}\text { Classificação quanto a } \\
\text { alfabetização em código }\end{array}$ & $\begin{array}{c}\text { Resultado da disciplina } \\
\text { MD }\end{array}$ \\
\hline $\mathrm{A} 01$ & 84,4 & ACod & 90,0 \\
\hline $\mathrm{A} 02$ & 78,8 & ACod & 77,0 \\
\hline $\mathrm{A} 03$ & 94,0 & ACod & 90,0 \\
\hline A04 & 59,7 & ACod & 84,0 \\
\hline $\mathrm{A} 05$ & 81,5 & ACod & 69,0 \\
\hline A06 & 53,3 & PCD & 77,0 \\
\hline $\mathrm{A} 07$ & 69,5 & ACod & 60,0 \\
\hline $\mathrm{A} 08$ & 84,5 & ACod & 81,0 \\
\hline A09 & 34,3 & Não atingiu & 50,0 \\
\hline A10 & 81,3 & ACod & 94,0 \\
\hline A11 & 48,8 & Não atingiu & 74,0 \\
\hline A12 & 78,0 & ACod & 69,0 \\
\hline A13 & 78,0 & ACod & 60,0 \\
\hline A14 & 90,5 & ACod & 69,0 \\
\hline A15 & 64,8 & ACod & 71,0 \\
\hline A16 & 84,3 & ACod & 97,0 \\
\hline A17 & 65,3 & ACod & 67,0 \\
\hline A18 & 50,0 & PCD & 69,0 \\
\hline A19 & 66,0 & ACod & 86,0 \\
\hline A20 & 79,4 & ACod & 89,0 \\
\hline A21 & 50,8 & Não atingiu & 87,0 \\
\hline Média & 70,3 & & 76,7 \\
\hline
\end{tabular}

A partir da análise da Tabela anterior, percebeu-se que as médias das avaliações, MD e curso, ficaram em valores próximos, sendo que $76,1 \%$ foram considerados como alfabetizados em código e somente dois sujeitos apresentaram o desenvolvimento do $\mathrm{PC}$, porém não através da programação, portanto classificados como PCD (Pensador Computacional Desplugado). Foram 3 alunos que não foi possível a sua avaliação sobre a apropriação do desenvolvimento do PC, que foram os sujeitos A09, A11 e A21. 
Retomando que o valor de referência para a classificação do sujeito em ACod e de aprovação na disciplina é de 60, percebe-se que o aluno A09 não atingiu este valor em ambas as avaliações. Já o A11, embora sua avaliação em MD tenha superado o valor referência (60) não conseguiu demonstrar esses conhecimentos no curso de PC. Para o sujeito A21 segue a mesma interpretação.

No Gráfico 1, os resultados são apresentados a partir do agrupamento da amostra por nacionalidade.

Gráfico 1 - Médias x nacionalidade.

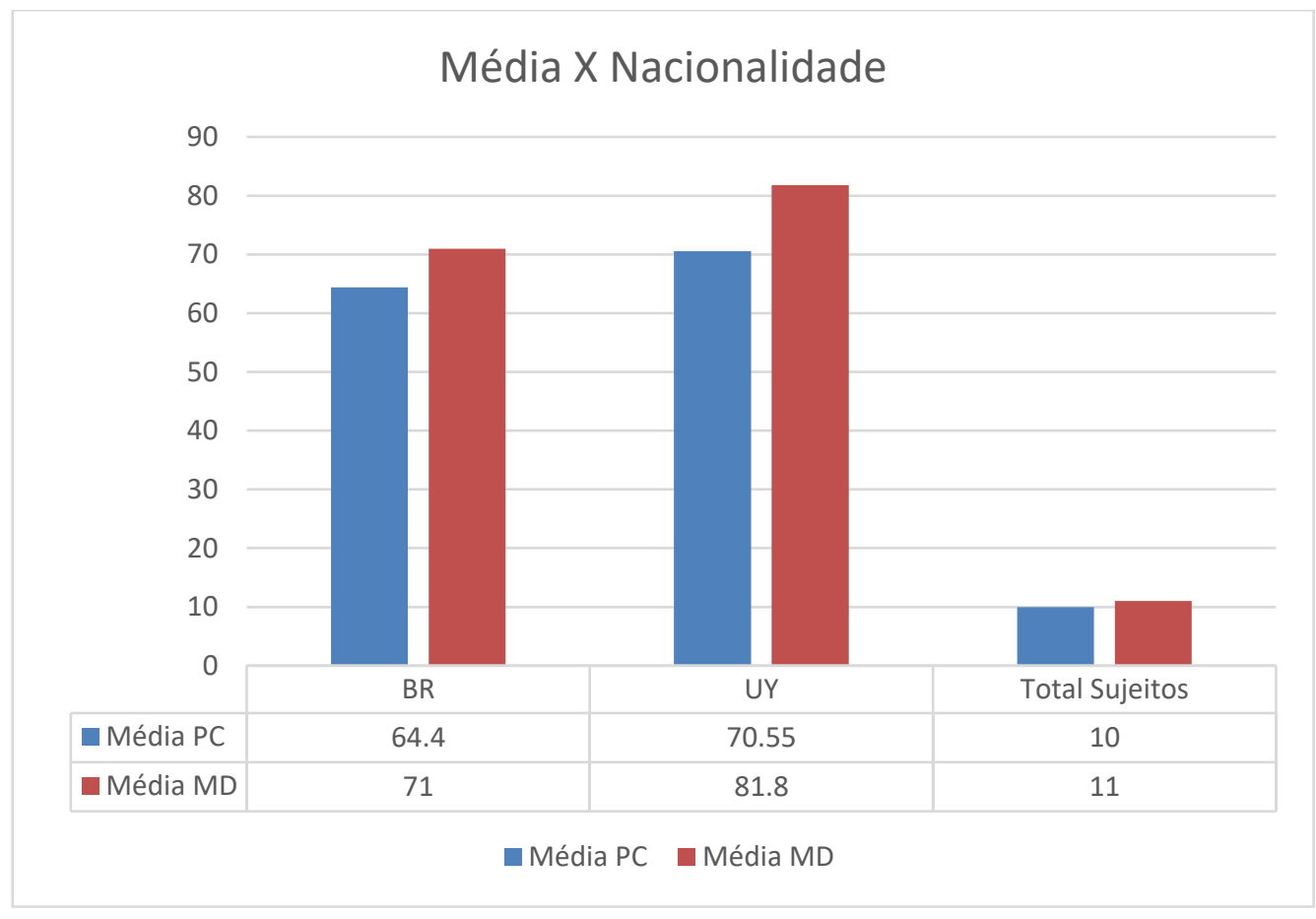

Como resultados da Avaliação Objetiva do PC, obteve-se uma média de 64,4 para os sujeitos brasileiros e 70,5 para o grupo de uruguaios. Já em MD os uruguaios apresentaram uma média de 81,8 , sendo $10 \%$ superior aos sujeitos brasileiros. Portanto, os índices dos alunos de nacionalidade uruguaia são mais altos se comparados aos alunos brasileiros. Porém, para confirmar esta conclusão, se faz necessário analisar os dados de outra maneira:

\begin{abstract}
Ao analisar os dados de uma amostra, devemos estar atentos ao fato de que algumas diferenças podem ser meramente casuais, ocasionadas por características próprias da amostra, não representando, necessariamente, propriedades da população que gostaríamos de conhecer. Neste contexto, torna-se importante estudarmos os chamados modelos probabilísticos [...], que constituem uma forma de mensurar a incerteza e, em consequência, fornecem uma metodologia adequada para generalizar resultados da amostra para a população (Barbetta, 2002, p. 16).
\end{abstract}

Apropriando-se dos conceitos abordados na Estatística Descritiva, na Tabela 3, podem ser visualizados os valores os quais representam os resultados obtidos a partir das variáveis contínuas (Stevenson, 2001) dos estudos de casos, ou seja, da amostra da população observada.

$\mathrm{Na}$ Tabela 3 é apresentada a estatística descritiva dos resultados do curso de PC e da MD. 
Tabela 3 - Estatística descritiva.

\begin{tabular}{|c|c|c|c|}
\hline \multicolumn{2}{|l|}{ Eu Programo 1.0! } & \multicolumn{2}{|l|}{$M D$} \\
\hline Média & 70,32 & Média & 76,67 \\
\hline Erro & 3,49 & Erro & 2,73 \\
\hline Mediana & 78,00 & Mediana & 77,00 \\
\hline Moda & 78,00 & Moda & 69,00 \\
\hline Desvio Padrão & 16,00 & Desvio Padrão & 12,50 \\
\hline Variância & 255,87 & Variância & 156,13 \\
\hline Coeficiente de assimetria & $-0,60$ & Coeficiente de assimetria & $-0,24$ \\
\hline Intervalo & 59,75 & Intervalo & 47,00 \\
\hline Mínimo & 34,25 & Mínimo & 50,00 \\
\hline Máximo & 94,00 & Máximo & 97,00 \\
\hline Soma & 1476,8 & Soma & 1610,0 \\
\hline Nível de Confiança $(95,0 \%)$ & 7,28 & Nível de Confiança $(95,0 \%)$ & 5,69 \\
\hline
\end{tabular}

Para prosseguir a análise quantitativa e a escolha dos tipos de testes a serem aplicados (paramétricos e não paramétricos), inicia-se verificando se as amostras atendem a uma distribuição normal, considerando-se que:

[...] é a implicação prática de uma diferença significativa estatisticamente. Uma diferença significativa é uma diferença que não deve ter ocorrido meramente por acaso, mas não, necessariamente, é uma diferença relevante em termos práticos. [...]. Resta a análise prática para verificar se estas diferenças, que podem ser estimadas pelos dados, são relevantes (Barbetta, 2002, p. 240).

Para os testes paramétricos é exigido que as amostras dos dados tenham uma distribuição normal, principalmente se tiverem uma dimensão (total da amostra) inferior a 30 (Moraes, 2016). Foi eleito o teste Shapiro-Wilk para testar a normalidade da amostra, pois apresenta melhor desempenho para discriminar a distribuição de amostra normal (Razali \& Wah, 2011). Para realizar o teste de Shapiro-Wilk, foram definidas duas hipóteses (Campos, 2000; Moraes, 2016):

$\mathbf{H}_{0}$ : A amostra provém de uma distribuição normal;

$\mathbf{H}_{1}$ : A amostra não provém de uma distribuição normal.

$\mathrm{O}$ valor resultante deste teste para o curso de PC foi de $\mathrm{p}=0,938$ e para o de MD foi de $\mathrm{p}=0,9651$, considerando um $\alpha=0,05$ (nível de significância). Logo, o valor de $\mathrm{p}$ (calculado) é maior que $\alpha$, portanto não é possível rejeitar a $\mathrm{H}_{0}$. Dessa forma, se pode afirmar que para um nível de confiança de $95 \%$ (ou significância de 5\%) a amostra provém de uma distribuição normal. A ilustração da distribuição normalizada da amostra total $(\mathrm{N}=21)$, para as duas intervenções, estão apresentadas no Gráfico 2 e no Gráfico 3, o qual revela que quanto mais perto os pontos estiverem do eixo central, maior a evidência da normalização dos dados. 


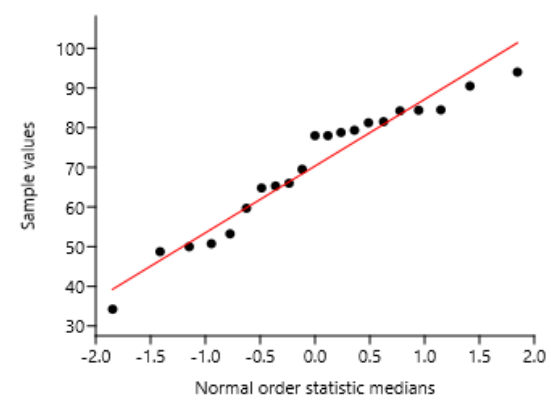

Gráfico 2 - Distribuição das avaliações do curso de PC.

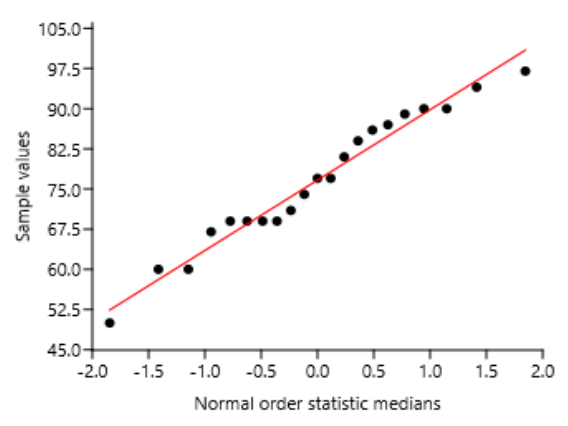

Gráfico 3 - Distribuição das avaliações da MD.

Considerando que os dados das amostras seguiram uma distribuição normal e a sugestão de Reis (2008) sobre o uso da distribuição " $t$ " de Student para pequenas amostras, este teste foi aplicado.

Considerando as seguintes hipóteses para o teste $t$ :

$\mathbf{H}_{0}: \mu \mathrm{EC} 1=\mu \mathrm{EC} 2$

$\mathbf{H}_{1}: \mu \mathrm{EC} 1 \neq \mu \mathrm{EC} 2$

Esclarecendo que $\mu \mathrm{EC} 1$ e $\mu \mathrm{EC} 2$ correspondem às médias populacionais e não às médias amostrais, a Tabela 4 apresenta o resultado do $t$ Student (amostras independentes) aplicado aos dados.

Tabela 4 - Teste t para duas amostras.

\begin{tabular}{ccc}
\hline & $P C$ & $M D$ \\
\hline Média & 70,3238095 & 76,6666667 \\
Variância & 255,872842 & 156,133333 \\
Observações & 21 & 21 \\
Variância agrupada & 206,003088 & \\
Diferencia hipotética das médias & 0 & \\
Grau de Liberdade & 40 & \\
Estatístico t & $-1,431999$ & \\
$\mathrm{P}(\mathrm{T}<=\mathrm{t})$ uma cauda & 0,07995626 & \\
Valor crítico de t (uma cauda) & 1,68385101 & \\
$\mathrm{P}(\mathrm{T}<=\mathrm{t})$ bicaudal & 0,15991253 & \\
Valor crítico de t (bicaudal) & 2,02107539 &
\end{tabular}

Observando que o valor de testatístico é igual a -1,431999 e o valor crítico de t (bicaudal) é de 2,02 , o primeiro valor se encontra no intervalo de $-2,02$ e $+2,02$, indicando uma distribuição normal. Usa-se o valor de $\mathrm{t}$ bicaudal ou bilateral, pois na hipótese $\mathrm{H}_{1}$ foi considerado o sinal “未” e portanto o valor de $p$ deve corresponder às duas caudas da distribuição (Barbetta, 2002).

Complementando, a regra $\mathrm{p}\left(\mathrm{t}<=\mathrm{t}_{\text {crítico }}\right)=0,15$ e o nível de significância de $\alpha=0,05$ indicam que Ho não é rejeitada. Em outras palavras, não há diferença significativa entre as médias. Logo, ambas interações foram alinhadas e bem desenvolvidas em ambos os estudos. 
A fim de complementar a análise e avaliação da interação interdisciplinar, fez-se algumas observações abordando a aprendizagem de MD no grupo que participou do curso de PC (nomeado de Turma 1) e o de controle (Turma2). Considerando que os dados obtidos foram coletados em turmas distintas, portanto, não podem ser avaliados apenas em função da média final de cada turma. Sendo assim, o Gráfico 4 e o Gráfico 5 apresentam a apropriação dos conhecimentos de cada turma.

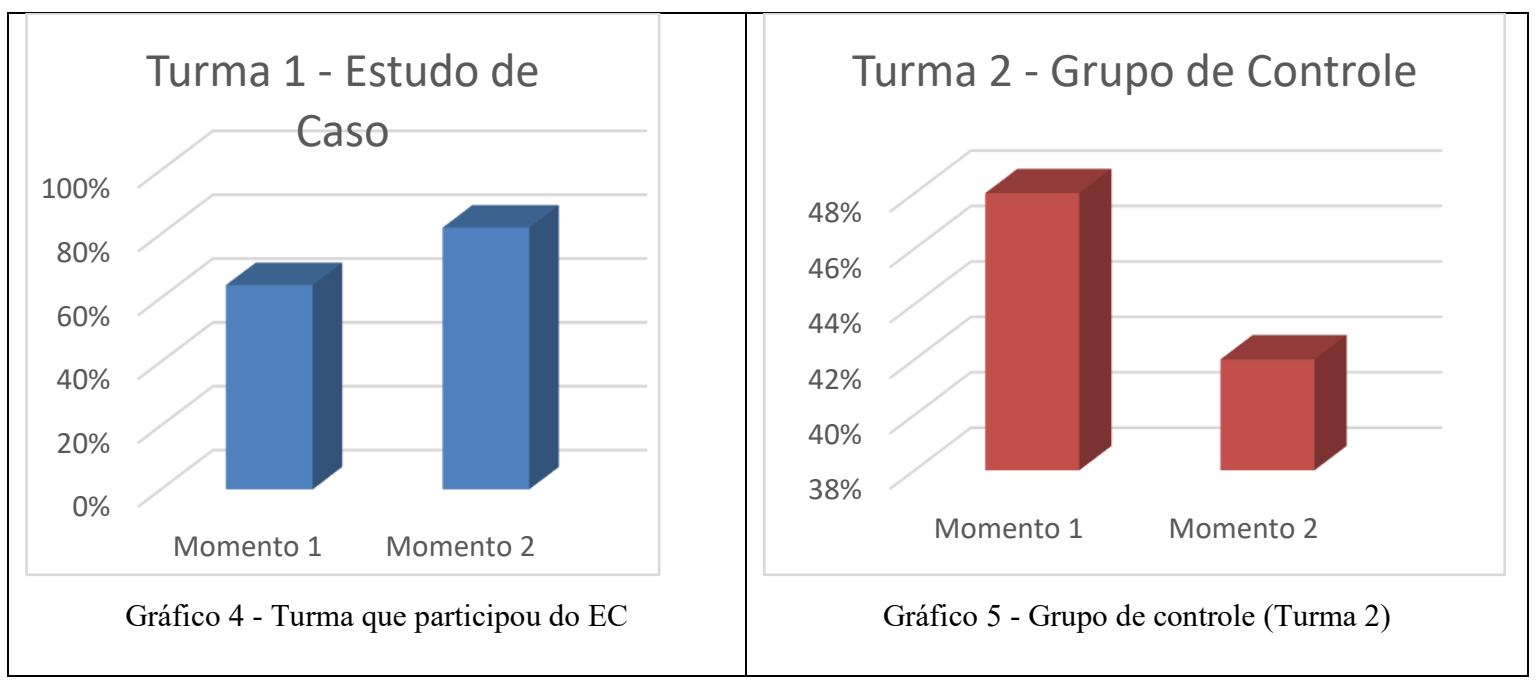

Nos gráficos a coluna "Momento 1", corresponde a parte introdutória da disciplina. Onde foram abordados conceitos, definições e estudo da lógica textual. Este último foi desenvolvido igualmente em ambas as turmas. Já a coluna "Momento 2" corresponde a aplicação dos conceitos estudados no Momento 1.

O chamado "Momento 2" foi desenvolvido através do curso "Eu Programo 1.0!", ou seja, através do EC. Já para o grupo de controle (Turma 2) foi explorado por meio de exercícios de livro didático, ou seja, aplicados na resolução de problemas de forma usual, em outras palavras, sem computador com representação puramente matemática. Os resultados podem ser visualizados no Gráfico 6.

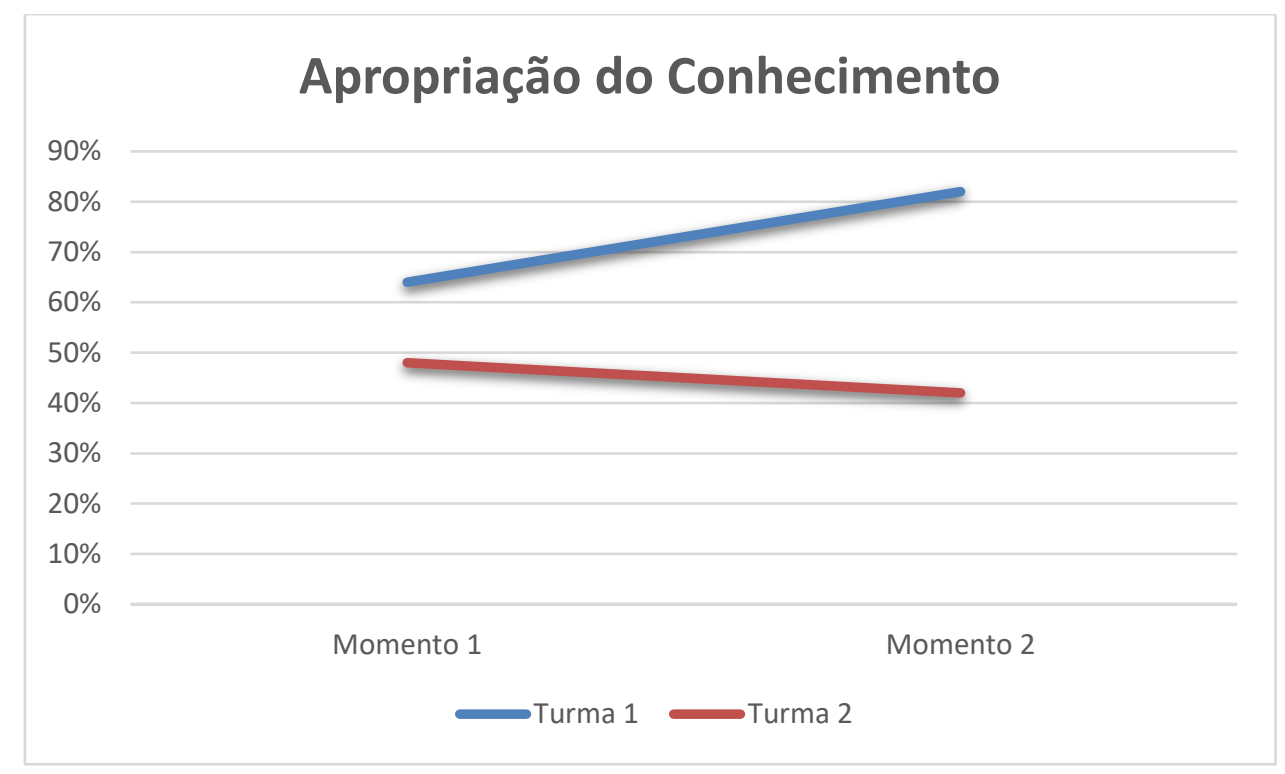

Gráfico 6 - Apropriação do Conhecimento 
Pode-se inferir que, a partir dos resultados do Gráfico 6, os sujeitos envolvidos no EC e, portanto, oportunizados em desenvolver o PC (Turma 1), apresentaram uma melhora significativa na compreensão sobre os conceitos estudados na MD. Por outro lado, a turma que não teve influência do PC (Turma 2) no desenvolvimento de $\mathrm{MD}$, ao se deparar com situações problemas, encontrou dificuldades em aplicar os conceitos, gerando assim uma redução das médias finais.

Quanto à avaliação qualitativa, notou-se, na turma 1, uma maior maturidade na compreensão e aplicação dos conceitos abordados na MD e a facilidade de relacioná-los às disciplinas técnicas, fazendo uso dos mesmos e de toda metodologia de resolução de problemas, desenvolvidas por meio do PC, para estruturar seus programas e aplicativos.

Considerando o exposto até então nesta seção, pode-se responder afirmativamente a hipótese formulada para esta pesquisa: o desenvolvimento do PC aporta impacto positivo no processo de compreensão dos temas trabalhados na MD.

Comparando a média aritmética obtida na disciplina de MD, com o grupo que trabalhou com PC, foi de 76,6. O grupo de controle obteve a média de 55,2, com uma amostra de 23 sujeitos participantes. Portanto, tem-se um valor significativamente superior nas notas dos alunos que tiveram a oportunidade de trabalhar com PC e com programação, ou seja, com conceitos próprios da ciência da computação e com a resolução de problemas. Conclui-se a importância do tema sobre PC, tanto abordado como na própria disciplina, bem como uma disciplina ministrada dissociada de outras disciplinas do curso.

A seguir as conclusões estão discorridas.

\section{Conclusão}

Este trabalho apresentou uma pesquisa sobre uma metodologia de trabalho interdisciplinar entre a disciplina de Matemática Discreta em um curso superior de Computação, aliada ao desenvolvimento do Pensamento Computacional. Esta metodologia foi embasada em diversos autores, entre eles, Ausubel (2003) e Knowles (2011), considerando a aprendizagem significativa de alunos adultos e suas peculiaridades e interesses.

A partir dos resultados, quanti-qualitativos, apresentados na seção anterior, pode-se concluir a relevância do processo de ensino e aprendizagem, apresentado neste estudo, ou seja, que a integração do PC com a MD, a partir de espaços compartilhados, foi um fator importante para o sucesso da aprendizagem dos alunos que participaram deste estudo, além de ancorar novos conhecimentos, de forma significativa.

Com o fechamento desta pesquisa, pode-se afirmar que os temas sobre resolução de problemas, PC, alfabetização em código, estão além de um entendimento técnico e/ou operacional, mas se debruçam sobre a questão de ser um cidadão participativo em uma sociedade tecnológica, evitando a marginalização de grupos minoritários. Além disso, acreditase que os profissionais da área de desenvolvimento de software (um programador, por exemplo) tendo que atender a diferentes funcionalidades e/ou demandas dos clientes, torna-se conveniente (e imprescindível) que transite por diferentes áreas, se apropriando de conceitos de vários campos do conhecimento, ou seja, um profissional interdisciplinar.

Finalizando as considerações, com referência ao trabalho dos pesquisadores Koh et al. (2010), no qual infere que as linguagens visuais não são adequadas para se obter de forma clara o tipo de conhecimento do qual o aluno se apropriou, após esta pesquisa, não se pode concordar com esta afirmação, uma vez que o uso do App Inventor foi uma escolha correta no sentido da motivação dos sujeitos em usá-la e aplicá-las nos seus smartphones, observadas no EC. 
Por fim, este estudo ocorreu na primeira turma do curso de TADS, que iniciou em 2019/01. A segunda entrada dos alunos, no semestre seguinte, constitui a chamada turma de controle, onde as interações não ocorreram, incluindo o terceiro ingresso no curso. Já na quarta turma (2020/2), novamente esta pesquisa retorna e devido a pandemia, o semestre está em andamento no momento da escrita desses resultados. Estes experimentos serão repetidos até julho de 2022, porém com algumas adaptações, visto que as interações deverão ocorrer de forma virtual.

\section{Agradecimentos}

Agradecemos ao Instituto Federal de Educação, Ciência e Tecnologia Sul-rio-grandense pelo apoio financeiro oferecido a tese de doutoramento.

\section{Referências}

Amaral, É. M. H. do. (2015). Processo de ensino e aprendizagem de algoritmos integrando ambientes imersivos e o paradigma de blocos de programação visual [Tese (Doutorado em Informática na Educação), Universidade Federal do Rio Grande do Sul]. doi: $\underline{10.5753 / \text { cbie.wcbie. } 2016.20}$

Araújo, A. L. S. O. de. (2019). Quantifying Computational Thinking Abilities [Tese (Doutorado em Ciência da Computação)]. Universidade Federal de Campina Grande. Recuperado de http://dspace.sti.ufcg.edu.br:8080/xmlui/handle/riufcg/17666

Ausubel, D. P. (2003). Aquisição e retenção de conhecimentos: Uma perspectiva cognitiva. Tradução de Lígia Teopisto (1st ed.). Plátano Edições Técnicas.

Barbetta, P. A. (2002). Estatística aplicada às Ciências Sociais (5th ed.). UFSC.

Barcelos, T. S. (2014). Relações entre o Pensamento Computacional e a Matemática em atividades didáticas de construção de jogos digitais [Tese (Doutorado em Ensino de Ciências e Matemática)]. Universidade Cruzeiro do Sul. Recuperado de https://www.academia.edu/31849410/Rela\%C3\%A7\%C3\%B5es_entre_o_Pensamento_ Computacional_e_a_Matem\%C3\%A1tica_uma_Revis\%C3\%A3o_Sistem\%C3\%A1tica da_Literatura

Campos, G. M. (2000, December 19). A escolha do teste mais adequado. Estatística Prática Para Docentes e Pós-Graduandos. Recuperado de http://www.forp.usp.br/restauradora/gmc/gmc_livro/gmc_livro_cap14.html

Cardoso, V. M, \& Cordenonzi, W. (2017). @ Prenda: Objeto de Aprendizagem aliado ao Ensino da Matemática. CONGRESO URUGUAYO DE EDUCACIÓN MATEMÁTICA. Recuperado de www.semur.edu.uy/curem/actas

Cardoso, Vanessa M., Cordenonzi, W., \& Gomez, S. (2017). Jogo @ prenda: um estudo de caso. VII Congresso Internacional de Ensino Da Matemática. Recuperado de https://www.researchgate.net/publication/324969435_Jogo_prenda_um_estudo_de_caso

Cavalcanti, R. de A. (1999). Andragogia: A aprendizagem nos adultos. Revista de Clínica Cirúrgica Da Paraíba, 6(4), 3-9. Recuperado de https://pt.slideshare.net/Vicentana/andragogia-a-aprendizagem-nos-adultos

Citolin, C. B. (2013). Eu Falo, Tu Hablas, Vos Hablás, Nós Ensinamos e Aprendemos Juntos: Aulas de Línguas em Cursos Binacionais [Tese (Doutorado em Educação)]. Universidade do Vale do Rio dos Sinos. Recuperado de http://www.repositorio.jesuita.org.br/handle/UNISINOS/3210 
Cordenonzi, W. H. (2020). O desenvolvimento do pensamento computacional e as evidências da alfabetização em código em adultos [Tese (Doutorado em Ensino)]. Universidade do Vale do Taquari - Univates.

Cordenonzi, W. H., Del Pino, J. C., Oliveira, E. C., \& Guimarães Strohschoen, A. A. (2020, April 22). Alfabetização - uma evolução do conceito: alfabetização e letramento em código. Texto Livre: Linguagem e Tecnologia, 13(1), 137. doi: 10.17851/1983$\underline{3652.13 .1 .137-155}$

Cordenonzi, W., Ortiz, A. M. C., Meneses, L., Gau de Mello, A., Luz Botasso, J. M. da, Mariani, V. de C. P., Gomez, R., \& Cross, V. (2014). Mapeamento da Educação Binacional - Relatório Técnico I. Recuperado de http://ecompartindo.santana.ifsul.edu.br/pluginfile.php/2328/mod_resource/content/3/rel atorio 1 - mapeamento da educação binacional.pdf

Costa, E. J. F. (2017). Pensamento Computacional na Educação Básica: Uma Abordagem para Estimular a Capacidade de Resolução de Problemas na Matemática [Dissertação (Mestrado em Ensino de Ciência da Computação)]. Universidade Federal de Campina Grande. Recuperado de http://dspace.sti.ufcg.edu.br:8080/jspui/handle/riufcg/1590

Delors, J., Al-Mufti, I., Amagi, I., Carneiro, R., Chung, F., Geremek, B., Gorham, W., Kornhauser, A., Manley, M., Quero, P. M., Savané, M.-A., Singh, K., Stavenhagen, R., Suhr, W. M., \& Nanzhao, Z. (1998). Educação: um tesouro a descobrir. Relatório para a UNESCO da Comissão Internacional sobre Educação para o Séc. XXI. In C. Editora (Ed.), Unesco da Comissão Internacional sobre Educação (1st ed.). Editora Cortez.

Ferreira Souza, V. (2018). Monitoria Geral 2017.2-Matemática Discreta e Lógica aplicada à Computação. In Seminário de Projetos de Ensino (ISSN: 2674-8134) (Vol. 3, Issue 1). Recuperado de https://periodicos.unifesspa.edu.br/index.php/spe/article/view/656

Gil, A. C. (2002). Como elaborar projetos de Pesquisa (4th ed.). Atlas.

Google. (2019). O blog do Google Brasil: Melhora nas habilidades digitais pode transformar a vida de milhares de brasileiros. Google. Recuperado de https://brasil.googleblog.com/2019/03/melhora-nas-habilidades-digitais-pode.html

Gouws, L., Bradshaw, K., \& Wentworth, P. (2013). First year student performance in a test for computational thinking. Proceedings of the South African Institute for Computer Scientists and Information Technologists Conference on - SAICSIT, 13, 271. doi: $\underline{10.1145 / 2513456.2513484}$

Grover, S., \& Pea, R. (2013, January 1). Computational Thinking in K-12. Educational Researcher, 42(1), 38-43. doi: 10.3102/0013189X12463051

Knowles, M. S. (1973). The adult learner: A neglected species. Gulf.

Knowles, M. S., Holton, E. F., \& Swamson, R. A. (2011). Aprendizagem de Resultados (2nd ed.). Elsevier.

Koh, K. H., Basawapatna, A., Bennett, V., \& Repenning, A. (2010). Towards the automatic recognition of computational thinking for adaptive visual language learning. Symposium on Visual Languages and Human-Centric Computing (VL/HCC), 59-66. doi: $\underline{10.1109 / \text { VLHCC.2010.17 }}$

Martins, H., Broide, J., Castilho, P., \& Dias, Y. (2019). Habilidades Digitais no Brasil | McKinsey. 1-49. Recuperado de https://www.mckinsey.com.br/our-insights/habilidadesdigitais-no-brasil

Mestre, P. A. A. (2017). O Uso do Pensamento Computacional como Estratégia para 
Resolução de Problemas Matemáticos [Dissertação (Mestrado em Ensino de Ciência da Computação)]. Universidade Federal de Campina Grande. Recuperado de http://dspace.sti.ufcg.edu.br:8080/jspui/handle/riufcg/696

Moraes, M. B. da C. (2016). Análise multivariada aplicada à contabilidade. Recuperado de https://edisciplinas.usp.br/pluginfile.php/1582605/mod_resource/content/1/AnáliseMulti variada-Aula01.pdf

Razali, N., \& Wah, Y. B. (2011). Power comparisons of Shapiro-Wilk, Kolmogorov-Smirnov, Lilliefors and Anderson-Darling tests. Journal of Statistical Modeling and Analytics, 2(1), $13-14$. Recuperado de https://www.researchgate.net/publication/267205556_Power_Comparisons_of_ShapiroWilk_Kolmogorov-Smirnov_Lilliefors_and_Anderson-Darling_Tests

Reis, M. M. (2008). Estatística aplicada à Administração (UFSC (ed.)). Departamento de Ciências da Administração- UFSC.

Silva, E. C. da. (2018). Pensamento computacional e a formação de conceitos matemáticos nos anos finais do Ensino Fundamental: Uma possibilidade com kits de robótica [Dissertação (Mestado em Educação Matemática)]. In Historia. Universidade Estadual Paulista "Júlio de Mesquita Filho". Recuperado de https://repositorio.unesp.br/handle/11449/180525

Silva, P. H. A., \& Lima, A. S. (2015). Cursos Binacionais: relatos de uma experiência inovadora. Editora Cia do eBook. Recuperado de https://www.researchgate.net/publication/283644603_Cursos_binacionais_relatos_de_u ma_experiencia_inovadora_livro

Stevenson, W. J. (2001). Estatística aplicada à Administração. Harbra.

Thiesen, J. da S. (2008). Interdisciplinary as an articulating movement in the teaching-learning process. Revista Brasileira de Educacao, 13(39), 545-554. doi: 10.1590/s1413$\underline{24782008000300010}$

Triviños, A. N. S. (2015). Introdução à pesquisa em Ciências Sociais - A pesquisa qualitativa em Educação. Atlas.

Van Dyne, M., \& Braun, J. (2014). Effectiveness of a computational thinking (CS0) course on student analytical skills. ACM Technical Symposium on Computer Science Education (SIGCSE), 45., 133-138. doi: $\underline{10.1145 / 2538862.2538956}$

Wilson, C., Grizzle, A., Tuazon, R., Akyempong, K., \& Cheung, C. K. (2011). Alfabetización mediática e informacional : curriculum para profesores. Organización de las Naciones Unidas para la Educación, la Ciencia y la Cultura, UNESCO. Recuperado de https://unesdoc.unesco.org/ark:/48223/pf0000216099

Wing, J. M. (2017, November 10). Computational thinking's influence on research and education for all. Italian Journal of Educational Technology, 25(2), 7-14. Recuperado de https://www.learntechlib.org/p/183466/ 